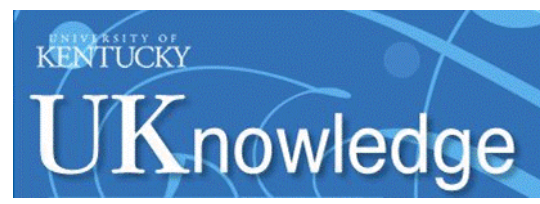

University of Kentucky

UKnowledge

$2-2014$

\title{
Metrics of the Gynecologic Oncology Literature Focused on Cited Utilization and Costs
}

\author{
Edward J. Pavlik \\ University of Kentucky, epaul1@uky.edu \\ John Hoff \\ University of Kentucky, john.hoff@uky.edu \\ Dylan Woolum \\ University of Kentucky, dylan.woolum@uky.edu \\ Yuqing Liang \\ University of Kentucky \\ Christiaan Wijers \\ University of Kentucky
}

See next page for additional authors

Follow this and additional works at: https://uknowledge.uky.edu/obgyn_facpub

Part of the Obstetrics and Gynecology Commons

Right click to open a feedback form in a new tab to let us know how this document benefits you.

\section{Repository Citation}

Pavlik, Edward J.; Hoff, John; Woolum, Dylan; Liang, Yuqing; Wijers, Christiaan; Schwartz, Melissa; Lefringhouse, Jason; and Baldwin, Lauren, "Metrics of the Gynecologic Oncology Literature Focused on Cited Utilization and Costs" (2014). Obstetrics and Gynecology Faculty Publications. 2.

https://uknowledge.uky.edu/obgyn_facpub/2

This Article is brought to you for free and open access by the Obstetrics and Gynecology at UKnowledge. It has been accepted for inclusion in Obstetrics and Gynecology Faculty Publications by an authorized administrator of UKnowledge. For more information, please contact UKnowledge@lsv.uky.edu. 


\title{
Metrics of the Gynecologic Oncology Literature Focused on Cited Utilization and Costs
}

\author{
Digital Object Identifier (DOI) \\ http://dx.doi.org/10.1016/j.ygyno.2013.12.008
}

\section{Notes/Citation Information}

Published in Gynecologic Oncology, v. 132, issue 2, p. 423-427.

Per the publisher Elsevier: "NOTICE: this is the author's version of a work that was accepted for publication in Gynecologic Oncology. Changes resulting from the publishing process, such as peer review, editing, corrections, structural formatting, and other quality control mechanisms may not be reflected in this document. Changes may have been made to this work since it was submitted for publication. A definitive version was subsequently published in Gynecologic Oncology, v. 132, issue 2, (February 2014). DOI: http://dx.doi.org/10.1016/j.ygyno.2013.12.008"

Tables in the article are downloadable as the additional file listed below.

\section{Authors}

Edward J. Pavlik, John Hoff, Dylan Woolum, Yuqing Liang, Christiaan Wijers, Melissa Schwartz, Jason Lefringhouse, and Lauren Baldwin 
Metrics of the gynecologic oncology literature focused on cited

\section{utilization and costs.}

\section{Edward J Pavlik*, John Hoff, Dylan Woolum, Yuqing Liang, Christiaan}

Wijers. Melissa Schwartz, Jason Lefringhouse and Lauren Baldwin

Short title: Utilization and cost of the gyn oncology literature

Key words: impact factor, eigenfactor, article influence score, costs

ORIGINAL REPORT

Precise: Utilization of the gyn oncology literature sources is influenced by access to review or summary information, the size of the specialty, and financial considerations.

Division of Gynecologic Oncology, Department of Obstetrics and Gynecology The University of Kentucky Chandler Medical Center Lexington, Kentucky 40536-0293

Correspondence to:

${ }^{\star}$ Edward J. Pavlik, Ph.D

Division of Gynecologic Oncology

Dept. of Obstetrics and Gynecology

University of Kentucky Medical Center 800 Rose Street

Lexington, KY 40536

Telephone 859/323-3830

Fax 859/323-1018

Email:epaul1@uky.edu

\section{ABSTRACT}


Objective: The newest findings on literature utilization relevant to gynecologic oncology were published by Thomson Reuters during June 2013 as determinants of journal standing. Our objective was to assess the different metrics reported for relative impact and cost for journals relevant to gynecologic oncology.

Methods: 55 journals were evaluated for Impact Factor (IF), 5 Year IF, Immediacy Index, Cited Half Life, Eigenfactor score (EF), Article Influence (Al) scores and subscription costs obtained from publisher information.

Results: CA-A Cancer Journal for Clinicians had the highest IF (101.78) \& AI (24.502).

The top EF cancer-specific journals were the Journal of Clinical Oncology, Cancer Research, Clinical Cancer Research and Oncogene. Rankings for Gynecologic Oncology (409 articles, 18,243 citations) were $\mathrm{IF}=3.929,43 / 55, \mathrm{EF}=0.038,28 / 55, \mathrm{Al}=$ $1.099,44 / 55$, all higher than the previous year. The IF improved from the 5 year IF in 31 journals, including Gynecologic Oncology, 29/31. Subscription costs for Gynecologic Oncology compared favorably to other journals.

Conclusions: The high utilization of review information in CA-A Cancer Journal for Clinicians and Nature Review Cancer illustrated by the IF coupled with a relatively low number of articles and short cited half life indicates that they serve as a leading source of quoted cancer statistics (CA-A Cancer Journal for Clinicians). Rankings for Gynecologic Oncology and the International Journal of Gynecologic Cancer have improved Regardless of specialty size, the Impact Factor for Gynecologic Oncology is respectably strong. The decreased IF in $44 \%$ of the journals may reflect the international economy's effect on cancer research. 


\section{Introduction}

55 The great commission of gynecologic oncology is to advance the field. To this end, new 56 information enters the literature and reaches individuals in practice and in training. We

57 have examined the extent to which this information is cited using information formulated

by Journal Citation Reports on the ISI Web of Knowledge [1]. In particular, this examination compares gynecologic oncology-specific citations to citations in a variety of journals that have published reports relevant to gynecologic oncology. The metrics considered here move considerations of quality and worthiness to readers beyond subjective views of reputation and command the attention of authors, sponsors and advertisers, while suggesting how metric improvement can be achieved.

\section{Methods}

The 55 journals selected for inclusion in this report all had published findings relevant to gynecologic oncology annually in the period in 2010-2012. Data on citations were obtained from Journal Citation Reports (JCR) on the ISI Web of Knowledge published by Thomson Reuters on subscription to the University of Kentucky libraries. The following definitions are used:

Impact Factor 2012 = A/B where

$A=$ the number of times that articles published in that journal in 2010 and 2011 were cited by articles in indexed journals during 2012 and

$B=$ the total number of "citable items" published by that journal in 2010 and 2011. ("Citable items" are usually articles, reviews, proceedings, or notes; not editorials or letters to the editor) [2]. 
5 Year Impact Factor: Average number of times articles from the journal published in the last five years have been cited in 2012. This measure can better gauge the impact of journals in fields where the influence of published research evolves over a longer period of time [3].

Immediacy Index 2012 = A/B where

$A=$ the number of times articles published by the journal in 2012 were cited in indexed journals during 2012

$B=$ the number of articles, reviews, proceedings or notes published by the journal in $2012[4]$.

Cited Half Life: the median age of the articles in the journal that were cited by other journals during 2012 [4].

Eigenfactor score: The Eigenfactor Score is measured using the 2012 citations in relation to citable items from the five previous years. While the Impact Factor weighs each citation to a journal equally, the Eigenfactor Score assigns a greater weight to those citations coming from influential journals, allowing these journals to exert greater influence in the determination of the rank of any journal which they reference. The Eigenfactor Score does not count journal self-citations. The sum of Eigenfactor Scores for all journals is 100; each journal's Eigenfactor Score is a percentage of this total $[5,6,7]$.

Article Influence Score: The journal's Eigenfactor Score divided by the fraction of articles published by the journal. This determination is normalized so that the sum total of articles from all journals is 1 [8]. 
Thus, the mean Article Influence Score is 1.00 across the universe of journals. Consequently, a score greater than 1.00 indicates that articles in that particular journal have above-average influence, while a score less than 1.00 indicates that articles in that journal have a below-average influence.

Cost Comparisons: Subscription costs were obtained by visiting the web sites for each publication. Cost of some institutional subscriptions were obtained from the University of Kentucky library.

\section{Results}

Metrics of Citation 55 journals were evaluated. The Proceedings of the National Academy of Science of the United States published the most articles (3800) in 2012, followed by the International Journal of Radiation Oncology Biology Physics (908), the International Journal of Cancer (713), Cancer (650), and Clinical Cancer Research (642), Table 1. Gynecologic Oncology published more articles in 2012 than 41 of the journals (380 articles), while the International Journal of Gynecologic Cancer published more articles than only 29 of the journals (236 articles). The articles cited in 2012 for publications in 2010-11 define the Impact Factor and CA-A Cancer Journal for Clinicians, the New England Journal of Medicine, the Lancet, Nature Review of Cancer and the Journal of the American Medical Association ranked with the highest Impact factors. Gynecologic Oncology ranked $43^{\text {rd }}$ with an Impact Factor of 3.929, while the International Journal of Gynecologic Cancer ranked $52^{\text {nd }}$ with an Impact Factor of 1.941, Table 1. Immediacy defined in terms of same year publication and citation was highest for CA-A Cancer Journal for Clinicians, the New England Journal of Medicine, the Lancet, the Journal of the American Medical Association and Lancet Oncology with 
122 Gynecologic Oncology ranking $42^{\text {nd }}$ and the International Journal of Gynecologic

123 Cancer ranking $54^{\text {th }}$. The staying power of articles as defined by the median age

124 published in other journals in 2012 (Cited Half Life, in years) was highest for the

125 American Journal of Obstetrics \& Gynecology, Cancer, the Journal of the National

126 Cancer Institute, Advances in Cancer Research and the Journal of the American

127 Medical Association with Gynecologic Oncology ranked $18^{\text {th }}$ and the International

128 Journal of Gynecologic Cancer ranked $33^{\text {rd }}$, Table 1. Journal citations over a five year

129 period weighted for influential journals (2008-2012: Eigenfactor score) were highest for

130 the Proceedings of the National Academy of Science of the United States, the New

131 England Journal of Medicine, the Journal of Clinical Oncology, Lancet, and Cancer

132 Research, while Gynecologic Oncology ranked $28^{\text {th }}$ and the International Journal of

133 Gynecologic Cancer ranked $40^{\text {th }}$. The Article Influence Score can be taken as a

134 measure of average influence of a journal's articles five years after publication and by

135 this measure CA-A Cancer Journal for Clinicians, the New England Journal of Medicine,

136 Nature Review Cancer, Lancet, Cancer Cell and the Journal of the American Medical

137 Association scored highest (>10), while Gynecologic Oncology demonstrated above

138 average influence and the International Journal of Gynecologic Cancer showed

139 influence well below average.

140 Our survey of the $2011-2012$ period revealed that $~ 15 \%$ of papers cited in Gynecologic

141 Oncology had been published in Gynecologic Oncology. In addition, surveying the

142 Gynecologic Oncology sections of the Journal of Clinical Oncology and of Cancer,

143 showed that $\sim 17 \%$ and $\sim 5 \%$ of the references were to papers published in Gynecologic

144 Oncology. 
Examination of Cost The most relevant subscription costs to gynecologic oncologists are likely to be Gynecologic Oncology \& the International Journal of Gynecologic Cancer (Table 2 line A), Cancer and the Journal of Oncology (Table 2 line B) and Obstetrics \& Gynecology and the American Journal of Obstetrics and Gynecology (Table 2 line C) totaling $\$ 2465$ for members, $\$ 3003$ for non-members and $\$ 8983$ for libraries (Table 2 line 3). The total subscription cost to libraries and institutions for all 55 journals considered here is $\$ 109,512$ and is $\sim 5$ times the cost to individual members (Table 2 line E). The mean cost to members of the 55 journals considered (Table 2 line F: $\$ 554 \pm 129$ (SEM)) compares well with the subscription cost of Gynecologic Oncology ( $\$ 563$ journal alone, $\$ 625$ annual membership with complementary journal subscription). However, subscription costs to the 6 journals most relevant to gynecologic oncology (Table 2 line $D$ ) are much less than the mean cost of subscription to 6 journals in the group of 55 journals under consideration (Table 2 line $\mathrm{G}$ ).

\section{Discussion}

Ranking of the top 10 Impact Factor journals correlated well with the 5 year Impact Factor, Immediacy Index and Article Influence Score in that the same journals ranked in the top 10 for each of these categories (Table 3). Only one of the top 10 Impact Factor journals was in the top 10 of the Number of Articles published in 2012, while 4 were in the top 10 of Total Citations in 2012 and 4 were in the top ten rank for Cited Half-life. Half of the top ten Impact Factor journals were among the journals with a top ten Eigen Factor score (Table 3). Thus, annual citation performance is least correlated with the number of articles published and connected about half the time with citations received, 
167 their median half life and Eigen Factor score. Consequently the metrics of citation are 168 not driven by the volume of articles published.

169 Gynecologic Oncology was above the median ranking in terms of articles published,

170 cited half-life and total citations for 2012 (Table 3), but it was below the median ranking

171 in all other measures. The International Journal of Gynecologic Cancer was above the

172 median ranking in articles published, but below the median ranking in all other

173 measures (Table 3).

174 Journals that publish reviews (CA-A Cancer Journal for Clinicians, Nature Review of

175 Cancer, Nature Reviews Clinical Oncology) are often cited with high immediacy and

176 short half-life because they are subject to annual updating (and do not necessarily occur

177 as citations in the most influential journals as indicated by the Eigen Factor metric).

178 Improvement in the current Impact Factor relative to the previous five years was

179 observed with 31 journals (56\%), while the citation rate fell in $44 \%$ of the journals

180 considered. Thus, a narrow $6 \%$ margin separates the journals that demonstrate

181 improving citation from those that do not. Two tactics that could serve Gynecologic

182 Oncology to stay on track with improving annual Impact Factor scores could be to

183 include more reviews on gynecologic malignancies and to implement the inclusion of

184 annual statistics on gynecologic malignancies. Such statistics should include and

185 expand the gynecologic malignancies reported on beyond those covered in $C A-A$

186 Cancer Journal for Clinicians so that statistics uniquely available in Gynecologic

187 Oncology would push its Impact Factor higher. Importantly, gynecologic cancer reviews

188 and gynecologic cancer statistics should be made available on an Open Access basis to 
maximize their utilization and contribution to the Impact Factor of Gynecologic Oncology.

Considered in the spectrum of medical specialty journals, Gynecologic Oncology is wellpositioned. Of twenty seven selected medical specialties that were examined (Table 4), gynecologic oncology which ranked $22^{\text {nd }}$ in physician number $(n=1007[9,10])$ had it's lead journal's Impact Factor ranked $13^{\text {th }}$. The Impact Factor for Gynecologic Oncology (3.929) was better than the median Impact Factor for journals in small specialties (491854 physicians, median = 2.649) and better than the median Impact Factor for the lead journals of all specialties considered here $($ median $=3.569)$. Mid sized specialties (4493-19131 physicians) had lead journals with a greater median Impact Factor (5.644). Large specialties (27651-90269 physicians) had a median Impact Factor (3.877) slightly lower than Gynecologic Oncology. Considered in these terms, the current Impact Factor for Gynecologic Oncology is quite strong and respectable among journals for medical specialties. Impact Factors >10 considered here (Table 1) were either for multispecialty journals or multi-discipline journals. We believe that Gynecologic Oncology currently serves both private practice and academic gynecologic oncologists extremely well because of it's targeted content. We also believe that as a group, gynecologic oncologists are proud and very competitive. In this regard, we feel that an expectation exists for journal metrics that continuously improve. We believe that there is no downside to improving these metrics for those in private practice as well as in academic medicine and that the better the journal metrics, the better the Society of Gynecologic Oncologists will fair in the eyes of advertisers and sponsors. 
211 In summary, Gynecologic Oncology performs well in terms of citation metrics and cost.

212 It should be possible to further improve these metrics by introducing reviews and

213 statistics on gynecologic malignancies.

214 The role of the medical journal must loom in the perspective of practitioners as a 215 trustworthy source of information that carries both influence and advice. In this role it 216 unifies the past with the present and must be counted on to have an ongoing outreach

217 to future discovery and innovation. Authors want to publish in a quality place that draws

218 attention to their work, a place that will be good enough to contribute to their career 219 advancement. Readers want a source of significant information that is worthy of their 220 time and subscription cost. The measure of quality and time worthiness has moved 221 beyond subjective evaluation and now takes on the metrics of utilization, which while 222 not totally perfect, provide comparative numeric standards that, like it or not, do 223 command attention, especially of sponsors and advertisers. Not to be overlooked are 224 new models embracing digital communication that have an influence on authors, 225 readers, patients, sponsors and advertisers through information that reaches them 226 through the Internet, Open Access, social media, blogs, Twitter, search engines, etc. In 227 the end, the metrics of citation utilization will both influence and be influenced by an 228 evolution of awareness brought forward by technology. As this occurs, journals must 229 not lose sight of the significance of peer review [2]. This is the single most important 230 process that can re-craft the submission by utilizing expert reviewers that raise 231 questions, the answers to which can be incorporated in the final publication to enhance 232 it's quality [11]. In the end, with the literature practically "bursting at the seams" with the 233 diverse opportunities made possible by the digital revolution [12], it will be quality that 
234 determines readership and citations. The future holds but one thing and that is to 235 continue to evolve so that specialty information is useful to those in the field of 236 gynecologic oncology [13].

239 Conflict of Interest Statement

240 The authors declare that there are no conflicts of interest. 


\section{References}

1. Garfield E. The evolution of the Science Citation Index. International Microbiology 2007;10: 65-69.

2. Groesser SN. Dynamics of Journal Impact Factors. Systems Research and Behavioral Science Syst Res 2012:29: 624-644.

3. van Nierop E. The introduction of the 5-year impact factor: does it benefit statistics journals? Statistica Neerlandica 2010; 64:71-76.

4 Glossary of Thomson Scientific Terminology. http://ipscience.thomsonreuters.com/support/patents/patinf/terms/\#l. retrieved 11/22/2013.

5. Bergstrom C. Eigenfactor Measuring the value and prestige of scholarly journals. College \& Research Libraries News 2007;68: 314-316.

6.. Bergstrom CT, West JD, Wiseman MA. The Eigenfactor ${ }^{\mathrm{TM}}$ Metrics. The Journal of Neuroscience 2008; 28: 11433-11434.

7. Fersht A. The most influential journals: Impact Factor and Eigenfactor. Proc Natl Acad Sci U S A. 2009;106: 6883-6884.

8 Eigenfactor $^{\mathrm{TM}}$ Score and Article Influence ${ }^{\mathrm{TM}}$ Score: Detailed methods. http://www.eigenfactor.org/methods.pdf, retrieved 10/01/2013.

9. Wallace AH, Havrilesky LJ, Valea FA, Barnett JC, Berchuck A, Myers ER. Projecting the Need for Gynecologic Oncologists for the Next 40 Years. Obstetrics and Gynecology 2010; 116:1366-1372.

10. US News and World report: Find a doctor by specialty.

http://health.usnews.com/doctors/specialists-index, retrieved 11/22/2013.

11. Bohannon J. Who's Afraid of Peer Review? Science 2013; 342: 60-65

12. Stone R, Jasny B. Scientific discourse: buckling at the seams. Science 2013;342:57.

13. Podolsky SH, Greene JA, Jones DS. The evolving roles of the medical journal. The New England Journal of Medicine. 2012; 366:1457-1461. 